\title{
A Study of Efficacy of Intraoperative Application of Mitomycin-C in Endoscopic Dacryocystorhinostomy
}

\author{
Harikesh Sharma, ${ }^{1}$ Ajay Mallick ${ }^{1}$
}

\section{Introduction}

$\underline{\text { ABSTRACT }}$

Common cause for failure of endonasal dacryocystorhinostomy is closure of the intranasal ostium usually due to granulation tissue formation. Attempts have been made to improve the success rate of lacrimal surgery by using different methods like using balloon catheters, lasers and antimetabolites. This study aims to see change in success rate with and without the use of using Mitomycin-C in endonasal Dacryocystorhinostomy (DCR) surgery.

Materials and Methods

Sixty patients of acquired chronic dacryocystitis with nasolacrimal duct blockage, in the age group of 11-50 yrs were taken for study. Patients were alternatively divided into two groups $A \& B$ (30 patients in each group). Endoscopic dacryocystorhinostomy with Mitomycin-C application was performed in Group A and without Mitomycin-C application in Group B patients. Subjective assessment for symptomatic improvement and objective analysis obtained from results of syringing. The result data was subjected to Student's t test and chi square analysis.

$\underline{\text { Result }}$

Age of patients varied from 11 to 50 yrs. The male to female ratio was 7:8 in group A while 2:3 in group B. The commonest age group was between 21-30 years in both the groups. After 12 month follow up the success rate was 93\% in both the groups. The results between the groups were found to be statistically not significant $(p>0.05)$.

Conclusion

Mitomycin C was used in this study to assess its efficacy in improving the results of endoscopic DCR. Mitomycin C did not have significant effect on the outcomes of endoscopic DCR surgery for chronic dacryocystitis.

$\underline{\text { Keywords }}$

Dacryocystitis; Dacryocystorhinostomy; Antimetabolites; Mitomycin

$\mathrm{E}$ piphora or imperfect drainage of tears is a very common condition and form an almost universal symptom of disease of the lacrimal passage. ${ }^{1}$ Its commonest cause is obstruction in the drainage channel of normally produced tear fluid. Obstruction of lacrimal pathway is either congenital or acquired. Congenital causes include conditions such as congenital nasolacrimal duct obstruction, lacrimal fistula, lacrimal duct cyst. ${ }^{2}$ Acquired causes may be primary or secondary. Primary is idiopathic while secondary acquired causes include infections, neoplasm, sarcoidosis, Wegener's granulomatosis and radiation therapy. ${ }^{3}$

Once dacryocystitis is well established it has little tendency to resolve with medical treatment and hence surgical treatment remains the only choice of management. ${ }^{4}$ Dacryocystorhinostomy (DCR) is the most popular surgical technique and endoscopic DCR represent a well established approach for this condition.

Despite its advantages, various causes of failure of endoscopic DCR have been mentioned. ${ }^{5}$ Osteotomy closure by granulation tissue has been reported as the most important region of failure in endoscopic DCR. ${ }^{5,6}$ Attempts have been made to improve the outcome by using balloon catheters, stents and antimetabolites. Modulation of wound healing response to prevent excessive scar formation plays a major role in endoscopic

1 - Army College of Medical Sciences and Base Hospital, Delhi Cantt., New Delhi-110010

Corresponding author:

Dr Ajay Mallick

email: mallick_doc@yahoo.com 
lacrimal surgery. ${ }^{7}$ Many studies have been done using Mitomycin-C as antimetabolites. However the results are variable. Mitomycin-C is an alkylating agent derived from Streptomyces caespitosus. The present study was conducted to evaluate the success rate and to compare the results of endoscopic DCR with and without intraoperative Mitomycin-C.

\section{Materials and Methods}

Sixty patients in the age group of 11-50 years, who presented with symptoms and signs suggestive of chronic dacryocystitis secondary to distal nasolacrimal duct blockage, refractory to medical treatment were taken up for study. The cases were mostly referred from the Dept of Ophthalmology. All patients were subjected to detailed history and clinical examination.

\section{Study design}

This prospective study was done in a tertiary care centre in North India comparing the results of two groups formed by alternate sampling of the patients with nasolacrimal duct obstruction, who underwentdacryocystorhinostomy.

\section{Establishing the diagnosis}

The initial evaluation of the degree and site of obstruction was evaluated by lacrimal sac syringing with saline.Reflux of fluid through the opposite punctum indicated distal nasolacrimal duct obstruction i.e., the obstruction was in the or beyond the common canaliculus. Reflux from the same punctum indicated proximal obstruction. If the fluid passed into the nose freely with no reflux into the eye, the lacrimal system was labelled as patent not requiring surgery. Thereafter probing was performed using the Bowman's probe for the cases where there was suspicion of distal obstruction.

The probe was inserted through the lower punctum and led towards the common canaliculus. If it stopped 'hard' against the bone, it ruled out the canalicular block. If it stopped 'soft', a blockage in the canaliculus was likely. Dye disappearance test was used for assessing functional patency. Dacryocysto-scintigraphy and imaging studies was used in cases where there was a doubt in the level of obstruction.

Cases of canaliculi block or normal flow into the nose were not considered in the study. The patients were alternatively assigned into two groups of 30 patients each preoperatively.

\section{Exclusion criteria}

Patients having following pathology were not included in the study: (a) Marked deviated nasal septum to same side, (b) Features of Chronic rhinosinusitis, (c) Nasal tumours, (d) History of previous DCR, (e) Cases diagnosed with canalicular block.

Group A patients underwent endoscopic dacryocystorhinostomy followed by application of Mitomycin-C $(0.5 \mathrm{mg} / \mathrm{ml}$ solution of Mitomycin-C applied at stoma site for 5 minutes). Group B patients underwent endoscopic dacryocystorhinostomy without application of Mitomycin-C. The diameter of the ostium and that of the healed ostium at follow up was measured using a Bowman probe No 000 which was marked at $1 \mathrm{~mm}$ intervals.

\section{Method of application of Mitomycin C}

A surgical sponge was embedded in $0.5 \mathrm{mg} / \mathrm{ml}$ solution of Mitomycin $\mathrm{C}$ and applied to the mucosal border of the osteotomy site for 5 minutes under endoscopic visualisation. Maximum care was taken in order to have all circumferential mucosa in contact with the sponge. After removal of the sponge, the area was irrigated thoroughly with saline solution. A change in the colour of the nasal mucosa from red to white-grey was visible immediately after application. Commercial Nasal haemostatic packs were given for 24 hours.

\section{Post-op care}

Patients were discharged on the next day, after removing the nasal pack. They were advised not to blow nose for 10 days post op. Antibiotic eye drops, steroid eye drops, and nasal decongestant drops were given for 7 days. Saline nasal spray twice daily was also used for 15 days to reduce crusting. Systemic antibiotics were not prescribed as a routine. Patients were reviewed on 7th day when endoscopic nasal toilet and sac syringing were done.

\section{Follow-up}

The patients were called for follow-up at 03, 06 and 12 months. The follow-up visit comprised inquiry into symptoms, nasal endoscopy, sac syringing, dye 
Table I: Age and Sex distribution

\begin{tabular}{|c|c|c|c|c|c|c|}
\hline \multirow{2}{*}{$\begin{array}{c}\text { AGE } \\
\text { RANGE }\end{array}$} & Male & Female & Total (\%) & Male & Female & Total (\%) \\
\hline $11-20$ & 4 & 2 & $6(20 \%)$ & 2 & 2 & $4(13.3 \%)$ \\
\hline $21-30$ & 5 & 9 & $14(46.6 \%)$ & 5 & 10 & $15(50 \%)$ \\
\hline $31-40$ & 2 & 3 & $5(16.7 \%)$ & 3 & 2 & $5(16.7 \%)$ \\
\hline $41-50$ & 3 & 2 & $5(16.7 \%)$ & 2 & 4 & $6(20 \%)$ \\
\hline Total & 14 & 16 & $30(100 \%)$ & 12 & 18 & $30(100 \%)$ \\
\hline
\end{tabular}

disappearance test and documentation of complications.

\section{Result}

Sixty patients of chronic dacryocystitis with nasolacrimal blockage as confirmed clinically with sac syringing and probing were included in the study. In this study the age of patients varied from 11 to 50 yrs. The male to female ratio was 7:8 in group A and 2:3 in group B. The commonest age group was $21-30$ years in both the groups. (Table I). All the cases presented with epiphora and blocked nasolacrimal duct as assessed clinically by sac syringing and probing (TableII). Observations were made regarding relief, complications or recurrence of symptoms and patients were evaluated subjectively and objectively.

Subjective assessment

Complete relief from symptoms

Partial relief from symptoms

No relief from symptoms

\section{Objective assessment}

Syringing of the lacrimal sac was performed postoperatively at 1 month, 6 months and 12 months. Results were analysed as per patency of flow of saline into the nose as under:-
Patent: when there was no resistance to the flow of fluid

Partially patent: when some fluid regurgitates through the punctum and some passed into nasal cavity.

Blocked: When the entire amount of fluid regurgitates through the punctum and no fluid passes to nasal cavity.

Measurement of ostium size at surgery and at 12 month follow up was another parameter recorded for objective assessment.

These two groups were compared according to sex, age, and follow up subjective and objective assessments.

Both groups showed satisfactory improvement in results in terms of subjective and objective assessments (TableIII). Average ostium size obtained was 35.2 $\mathrm{mm}^{2}$ in the Mitomycin $\mathrm{C}$ treated group and $35.0 \mathrm{~mm}^{2}$ in the untreated group. Healed intranasal ostium sizes measured in the follow up examinations were $1.6 \mathrm{~mm}^{2}$ and $1.4 \mathrm{~mm}^{2}$ respectively. There was no statistical difference between them according to Student's t test $(p>0.05)$. The success rate in the Mitomycin $C$ treated group and the non-Mitomycin C treated group were 93\% on 12 months follow up, i.e. there was no significant difference in in the results of outcomes with or without the intraoperative use of Mitomycin- $\mathrm{C}$ in endoscopic DCR (Fisher's exact $\chi 2$ test, $p>0.05$ ). No nasal or other systemic effects of Mitomycin-C were observed during or after its application. 
Table II: Clinical presentation

\begin{tabular}{|c|c|c|}
\hline PRESENTING SYMPTOMS & GROUP A (N=30) & GROUP B (N=30) \\
\hline Epiphora & $\mathbf{3 0}$ & 9 \\
\hline Purulent discharge & $\mathbf{4}$ & 4 \\
\hline External swelling & 4 & GROUP B (N=30) \\
\hline CLINICAL FINDINGS & GROUP A (N=30) & 3 \\
\hline Swelling Lacrimal fossa area & 4 & 11 \\
\hline Rischarge on pressure in lacrimal fossa area & 13 & 30 \\
\hline
\end{tabular}

Fisher's exact $\chi 2$ test, $p>0.05$ - not significant

Table III: Results

\begin{tabular}{|c|c|c|c|c|c|c|}
\hline \multirow{2}{*}{$\begin{array}{c}\text { SUBJECTIVE } \\
\text { IMPROVEMENT }\end{array}$} & \multicolumn{3}{|c|}{ GROUPA $(\mathbf{N}=\mathbf{3 0})$} & \multicolumn{3}{|c|}{ GROUP B $(\mathbf{N}=30)$} \\
\hline & 1month & 6month & 12 month & 1month & 6month & 12 month \\
\hline $\begin{array}{c}\text { No of patients with complete } \\
\text { relief }\end{array}$ & 26 & 28 & 28 & 27 & 28 & 28 \\
\hline $\begin{array}{l}\text { No of patients with partial } \\
\text { relief }\end{array}$ & 4 & 2 & 1 & 3 & 1 & $\mathbf{0}$ \\
\hline No of patients with no relief & $\mathbf{0}$ & $\mathbf{0}$ & 1 & $\mathbf{0}$ & 1 & 2 \\
\hline $\begin{array}{l}\text { OBJECTIVE } \\
\text { IMPROVEMENT }\end{array}$ & \multicolumn{3}{|c|}{ GROUPA $(\mathbf{N}=\mathbf{3 0})$} & \multicolumn{3}{|c|}{ GROUP B (N=30) } \\
\hline (ON SYRINGING) & 1month & 6month & 12month & 1month & 6month & 12month \\
\hline Free flow into nose & 26 & 28 & 28 & 27 & 28 & 28 \\
\hline Partially blocked & 3 & 1 & 1 & 3 & 1 & $\mathbf{0}$ \\
\hline Blocked & 1 & 1 & 1 & $\mathbf{0}$ & 1 & 2 \\
\hline
\end{tabular}




\section{Discussion}

The decrease in the size of the healed intranasal ostium after DCR surgery is the result of a normal wound healing response. Recurrent nasolacrimal duct obstruction after primary DCR is mainly due to reclosure of the nasolacrimal stoma and osteotomy site with granulation tissue. ${ }^{8}$ One of the attempts to prevent closure of the stoma is local application of Antimetabolitesfor the inhibition of the wound healing process and the prevention of excessive scar formation in the rhinostomy site.

Mitomycin-C is an anti-neoplastic antibiotic agent isolated from soil bacterium Streptomyces caespitosus. It is an anti-metabolite with anti-proliferative effect on cells showing the highest rate of mitosis by inhibiting DNA synthesis and interferes with RNA transcription and protein synthesis. The cell cycle is most affected during the late G-I and early S-phase. The chemical formula is $\mathrm{C}_{15} \mathrm{H}_{18} \mathrm{~N}_{4} \mathrm{O}_{5}$. Mitomycin is available as a drypowder mixture of Mitomycin and mannitol in the ratio 1:2. On reconstitution with normal saline, each $\mathrm{ml}$ will contain $0.5 \mathrm{mg}$ Mitomycin with a $\mathrm{pH}$ between 6.0 $-8.0 .^{9}$

Use of Mitomycin-C in endoscopic DCR has been studied earlier but the results are varied. Zilelioglu et $\mathrm{al}^{7}$ reported a success rate of $77.3 \%$ in Mitomycin-C group and $77.8 \%$ in control group. They conclude the use of Mitomycin-C seems to be easy and safe. But the study did not show any benefit of using it. Camara et $\mathrm{a}^{10}$ reported a success rate of $99.2 \%$ in Mitomycin -C group and $89.6 \%$ in control group. Their study supports the safety and efficacy of intraoperative use of Mitomycin-C in endonasal DCR. Liao et a $1^{11}$ reported a success rate of $95.5 \%$ in Mitomycin-C group and $70.5 \%$ in control group. They conclude that intraoperative Mitomycin-C application is effective in increasing success rate of DCR surgery. Kao et $\mathrm{al}^{12}$ performed DCR on fifteen eyes. The success rate was $100 \%$ in Mitomycin-C group while in control group it was $87.5 \%$. Roozitalab MH et al ${ }^{13}$ reported 130 patients with nasolacrimal duct obstruction undergoing lacrimal surgery. The success rate in Mitomycin-C group was $90.5 \%$ while in control group it was $92.4 \%$. Ghosh et al did not find any statistical difference with the use of Mitomycin-C in their study of thirty cases. ${ }^{14}$

Thus, different studies have different opinion regarding efficacy of using Mitomycin-C. In our study we included sixty patients of chronic dacryocystitis showing features of nasolacrimal duct obstruction. We divided patients into two group (A \& B) of 30 patients each. A group underwent endoscopic DCR with intraoperative Mitomycin-C application while group B underwent endoscopic DCR without Mitomycin-C. We used Mitomycin-C in concentration of $0.5 \mathrm{mg} / \mathrm{ml}$ for five minutes at the stoma site. Patients were evaluated subjectively and objectively at 1,6 and 12 months post surgery. At the end of 12 months the success rate was same in both study as well as in control group. There were no major intraoperative or postoperative complications in both groups.

The mean ostium size in our series was around 35.1 $\mathrm{mm}^{2}$. Welham and Wulc ${ }^{15}$ noted that the scarring of the rhinostomy site was one of the reasons for failed external DCR. Exuberant scarring caused failure in $93 \%$ of 15 patients who had undergone secondary surgery in their series. Majority of the surgical failures in Endoscopic DCR surgery occurs within 4 months. ${ }^{5,6}$ These studies reported that the average onset of ostium closure after the primary operation was 6 to 26 weeks (mean 12.7 weeks). No patient in our series had ostium closure after 16 postoperative weeks. All of these findings indicated that the critical period was 4 - 6 months after endoscopic surgery.

\section{Conclusion}

Endoscopic DCR represent a new and promising approach for treatment of chronic dacryocystitis. Attempt has been made to improve the success rate of lacrimal surgery by using stents, laser and antimetabolites to prevent closure of the stoma. We used Mitomycin-C in our study. After 12 months of follow up period, the present study did not show any additional benefit of using Mitomycin-C at stoma site in endonasal DCR in terms of success rate. However a longer follow up must be undertaken before a definite conclusion can be made. A larger multicentric study is essential to establish the efficacy Mitomycin-C in endoscopic DCR success. 


\section{References}

1. Duke-Elder S. Diseases of the lacrimal passages. System of Ophthalmology.London: Henry Kimpton; 1965 p.675-93

2. Kapadia MK, Freitag SK, Woog JJ. Evaluation and management of congenital nasolacrimal duct obstruction. Otolaryngol Clin N Am. 2006; 39(5):959-77

3. Mills DM, Meyer DR. Acquired nasolacrimal duct obstruction. Otolaryngol Clin N Am. 2006; 39:979-99

4. Tanebaum M, McCord CD Jr. The lacrimal drainage system. In: Tasman W, Jaeger EA Editors. Duane's Clinical Ophthalmology. Philadelphia:Lippincott Raven; 1996. p.4/13/1-31

5. Bouch GA, Bradlev NL, Dortzbach RK. Results of endonasal laser assisted dacryocystorhinostomy. Ophthalmology 1994; 101:955-9

6. Kong YT, Kim TI, Byung WK. A report of 131 cases of endoscopic laser lacrimal surgery. Ophthalmology 1994; 101:1793-800

7. Zilelioglu G, Ugurbas SI, Anadolu Y, Akiner M, Akturk T. Adjunctive use of Mitomycin-C on endoscopic lacrimal surgery. Br J. Ophthalmol. 1998; 82:63-6
8. Ozkiris M, Ozkiris A, Göktas S. Effect of Mitomycin C on revision endoscopic dacryocystorhinostomy. J Craniofac Surg. 2012; 23(6):e608-10

9. Singh P, Singh A. Mitomycin-C Use in Ophthalmology. IOSR Journal of Pharmacy 2013; 3(1):12-14

10. Camara JG, Bengzon AU, Henson RD. The safety and efficacy of Mitomycin-C in endonasal endoscopic laser assisted dacryocystorhinostomy. Ophthal Plast Reconstr Surg. 2000; 16:114-8

11. Liao SL, Kao SCS, Tseng JHS, Chen MS, Hou PK. Results of intraoperative Mitomycin-C applicartion in dacryocystorhinostomy. Br J Ophthalmol. 2000; 84:903-6

12. Kao SCS, Liao CL, Tseng JHS, Chen MS et al. Dacryocystorhinostomy with intraoperative Mitomycin-C. Ophthalmology 1997; 104:86-91

13. Roozitalab MH, Amirahmadi M, Namazi MR. Results of the application of intraoperative Mitomycin-C in dacryocystorhinostomy. Eur J Ophthalmol. 2004; 14:461-3

14. Ghosh S, Roychoudhury A, Roychaudhuri BK. Use of Mitomycin C in endo-DCR. Indian J Otolaryngol Head Neck Surg. 2006; 58(4):368-9

15. Welham RA, Wulc AE. Management of unsuccessful lacrimal surgery. Br J Ophthalmol. 1987; 71:152-7. 